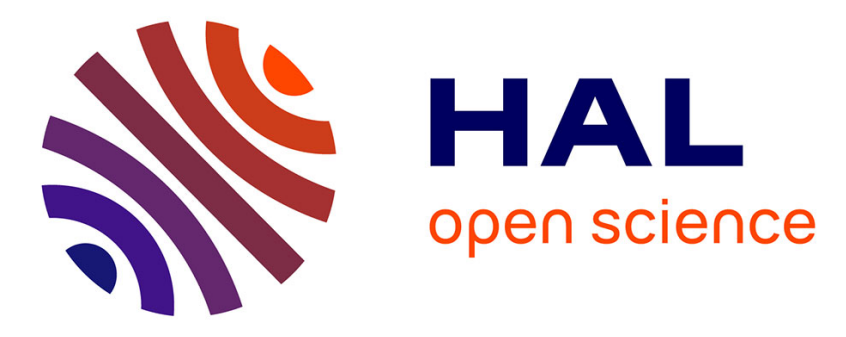

\title{
Cloud cover observed simultaneously from POLDER and METEOSAT
}

Geneviève Sèze, Claudine Vanbauce, Jean-Claude Buriez, Frédéric Parol, Pierre Couvert

\section{- To cite this version:}

Geneviève Sèze, Claudine Vanbauce, Jean-Claude Buriez, Frédéric Parol, Pierre Couvert. Cloud cover observed simultaneously from POLDER and METEOSAT. Physics and Chemistry of the Earth Part B Hydrology Oceans and Atmosphere, 1999, 24 (8), pp.921-926. 10.1016/S1464-1909(99)00104-5 . hal-00811410

\section{HAL Id: hal-00811410 https://hal.science/hal-00811410}

Submitted on 10 Apr 2013

HAL is a multi-disciplinary open access archive for the deposit and dissemination of scientific research documents, whether they are published or not. The documents may come from teaching and research institutions in France or abroad, or from public or private research centers.
L'archive ouverte pluridisciplinaire HAL, est destinée au dépôt et à la diffusion de documents scientifiques de niveau recherche, publiés ou non, émanant des établissements d'enseignement et de recherche français ou étrangers, des laboratoires publics ou privés. 


\title{
Cloud Cover Observed Simultaneously from POLDER and METEOSAT
}

\author{
G. Sèze ${ }^{1}$, C. Vanbauce ${ }^{2}$, J. C. Buriez ${ }^{2}$, F. Parol ${ }^{2}$ and P. Couvert ${ }^{3}$ \\ ${ }^{1}$ Laboratoire de Météorologie Dynamique, Université Pierre et Marie Curie, Paris, France \\ ${ }^{2}$ Laboratoire d'Optique Atmosphérique, Université des Sciences et Technologies de Lille, France \\ ${ }^{3}$ Laboratoire des Sciences du Climat et de l'Environnement, Centre d'Etudes de Saclay, France
}

Received 12 July 1998; accepted 25 February 1999

\begin{abstract}
The POLDER instrument that was aboard the Japanese ADEOS platform between August 1996 and June 1997. is designed to the global observations of the polarisation and directionality of the sun-light reflected by the Earth-atmosphere system. The cloud detection from POLDER takes advantage of the original capabilities of the instrument (spectral polarisation and directionality). This cloud detection scheme uses 5 threshold tests based on pressure, reflectance, polarised reflectance and spectral variability. The results of the POLDER cloud detection scheme are compared to those of the LMD dynamical clustering method applied to visible and infrared METEOSAT data and local spatial variability of these two parameters. Special focus is given to the detection capabilities of the two kind of measurements for cloud situations such as small cumulus, thin cirrus and multilayered cloud cover. Results of this comparison would give some insight on the behaviour of the International Satellite Cloud Climatology Project (ISCCP) cloud detection scheme built mainly from visible and infrared measurements.
\end{abstract}

C 1999 Elsevier Science Ltd. All rights reserved.

\section{Introduction}

Clouds form an essential component of the radiation halance of the Earth atmosphere. Consequently, a good knowledge of the role of clouds in the global climate system is necessary. Satellites can directly observe not only the spatial and temporal variabilities of clouds but also their effects on Earth's radiation balance at the top of the atmosphere. Such projects as ISCCP (International Satellite

Correspondence to: Geneviève Sèze. LMD, Tour 15, Université Pierre \& Marie Curie, 4 Place Jussieu, 75252 Paris Cedex 05, France.

Phone : (33) I 44272799 ; Fax : (33) 144276272

E-mail : Genevieve.Seze@Imd.jussieu.fi
Cloud Climatology Project, Schiffer and Rossow, 1983) and ERBE (Earth Radiation Budget Experiment, Barkstrom and Simith, 1986) have provided essential datasets allowing improving our understanding of the cloud-radiation-climate system. As a component of the new generation of earthorbiting instruments designed for Earth's observation, the POLDER (Polarization and Directionality of the Earth's Reflectances) radiometer was on-board the Japanese ADEOS platform from August 1996 to June 1997. This instrument consists of a CCD matrix detector, a rotating wheel that carries spectral filters and polarizers and a wide field-of-view lens. When the satellite passes over a target, up to 14 different images are acquired in eight narrow spectral bands of the visible and near-infrared spectrum (Deschamps et al, 1994).

The POLDER level I products routinely processed by the French Space Centre (CNES) consist of calibrated radiances at $6.2 \mathrm{~km}$ resolution. The level 2 and 3 products are split in three processing lines: "Earth Radiation Budget, water vapour and clouds" (hereafter "ERB \& clouds"), "Ocean color and aerosols over ocean", "Land surfaces and aerosols over land". An overview of algorithms and products of the "ERB \& clouds" line is presented in Buriez et al. (1997) and Parol et al. (1999). In August 1998 at the end of a validation period, the complete set of POLDER data will be processed by CNES and level 2 and 3 products will be made available to the scientific community.

As the majority of the analysis methods of cloud satellite observations the cloud detection phase is the first step of the "ERB \& clouds" algorithm. This paper focuses on the results of this cloud detection scheme. It is illustrated using POLDER data acquired on 10 November 1996 especially along three ADEOS orbits (orbit numbers 3107 to 3109). These orbits correspond to paths over the Atlantic Ocean, West Europe, West Africa, and Brazil, i.e. within the METEOSAT field of view (see Fig. 1).

The tests involved in the POLDER cloud detection algorithm are presented in section 2. A first validation of the pixel identitication is emphasised through comparison with the results of the Dynamical Clustering Method 


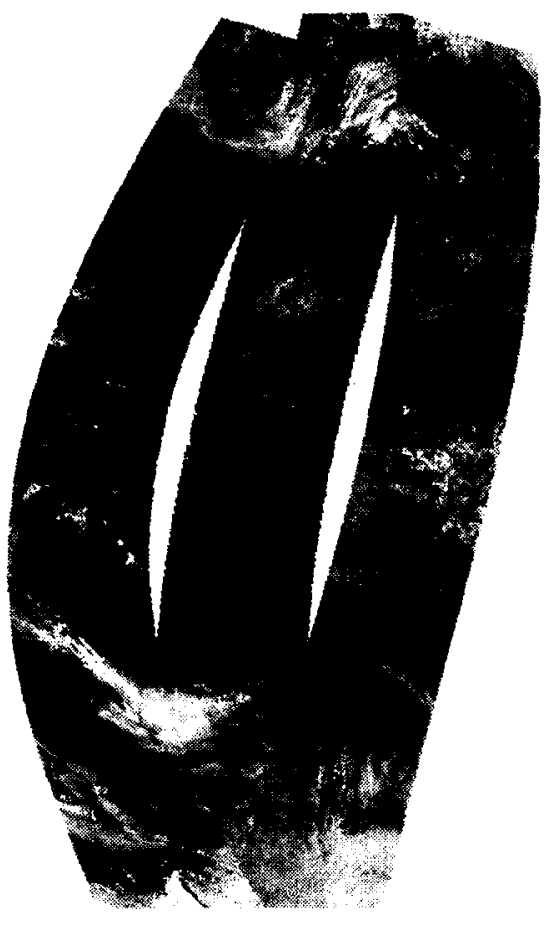

Fig.1. Image constructed from $670 \mathrm{~nm}$ reflectance measured by POLDER on 10 November 1996 along three ADEOS paths (orbit numbers 3107 to 3109) over the Atlantic Ocean. Clouds appear as light shades against a darker ucean or land background.

applied to METEOSAT satellite observations (Sèze and Desbois, 1987). Section 3 corresponds to a brief presentation of the classification method. Section 4 presents the comparison of the two cloud identification schemes. Finally, section 5 discusses the results and presents conclusions.

\section{The POLDER pixel identification algorithm}

The "ERB \& clouds" thematic interest takes advantage of the multi-spectral, multi-directional and multi-polarisation capabilities of POLDER to derive useful information on clouds and their effects on short-wave radiation (Parol et al, 1998). The first stage of the "ERB \& clouds" line is the recognition of cloud-contaminated pixels. This step is crucial since it controls further processing and it has a major impact on determining others products. Therefore particular attention is here given to this algorithm. It is a threshold method employing several sequential tests for the presence of clouds. The physical principles of the method are extensively developed in (Buriez et al, 1997). They were based on the analysis of measurements performed by the airborne simulator of POLDER. Since then, POLDER has flown aboard ADEOS and some adjustments and improvements have been brought to the algorithm. This section briefly covers the different threshold tests used in the algorithm and presents the methodology applied to adjust the various threshold values. This consists mainly in analysing the coherence of results from the various tests involved in the algorithm.

The cloud detection algorithm is based on a series of sequential threshold tests applied to each individual pixel $(6.2 \mathrm{~km})$ and for every viewing direction (see Fig. 2). Four tests aim at detecting clouds and a pixel is declared cloudy if one of these tests proves positive:

(i) An "apparent" pressure $P_{a p p}$ is derived from the ratio of reflectance measured in the channels centred at $763 \mathrm{~nm}$ and $765 \mathrm{~nm}$ (Buriez et al, 1997). The pixel is labelled cloudy if $P_{\text {app }}$ is markedly lower than the sea-surface pressure $P_{\text {surface. }}$ The threshold applied to $P_{\text {surface }}-P_{\text {app }}$ depends on the ratio between the molecular and the total reflectance at $765 \mathrm{~nm}, \mathrm{R}_{\mathrm{mol}} / \mathrm{R}$ * (Vanbauce et al, 1998) (see Fig. 3.a).

(ii) A pixel is declared cloudy if the measured reflectance at wavelength $\lambda, R_{\lambda}(\lambda=865 \mathrm{~nm}$ over ocean and $\lambda=443$ $\mathrm{nm}$ over land) is significantly larger than its clear-sky estimate $\mathrm{R}_{\lambda}^{\text {clear }}$. Over ocean, a large threshold value (10\%) is chosen in order to avoid classifying aerosols as clouds. The same value is chosen over land, but the spatial variability is taken into account.

(iii) For scattering angles less than $140^{\circ}$, the molecular optical thickness $\tau_{443}$ of the atmospheric layer above the observed surface (cloud or sea-surface) is directly derived from the polarised reflectance at $443 \mathrm{~nm}$. It is compared to the total molecular optical thickness of the atmosphere $\tau_{443}^{\text {clear }}$. If the $\tau_{443}^{\text {clear }}-\tau_{443}$ difference is above a certain threshold the pixel is rejected as cloudy. In Buriez et al. (1997) the threshold was set to a constant value. It varies as the air-mass factor in the new version of the algorithm.

(iv) The polarised radiance at $865 \mathrm{~nm}$ presents features different for clear-sky and for liquid water cloud conditions notably in the rainbow direction (Goloub et al, 1994). A pixel is identified as cloud-contaminated if the actual polarised radiance is outside the expected range for clearsky conditions. Figure $3 . \mathrm{h}$ shows that this range is now defined as a function of the scattering angle.

If all of the previous tests prove negative, two more tests are added in order to identify the clear pixels:

(v) A pixel that has not been declared cloudy is labelled as clear if $\mathrm{R}_{\lambda}-\mathrm{R}_{\lambda}^{\text {clear }}(\lambda=865 \mathrm{~nm}$ over ocean and $\lambda=$ $443 \mathrm{~nm}$ over land) is weak enough $(<2 \%)$.

(vi) Finally, a pixel is expected to be clear if its reflectance presents a large spectral variability. Practically, the $R_{865} / R_{443}$ ratio was found to be a better indicator than the $R_{865} / R_{670}$ ratio initially considered in Buriez et al. (1997). Over ocean, a pixel is declared as cloud-free if the $R_{865} / R_{443}$ ratio is less than 0.35 . This ratio has to be more than 2.2 over land surface.

The different thresholds above-presented have adjusted by applying the following philosophy. When adjusting the 


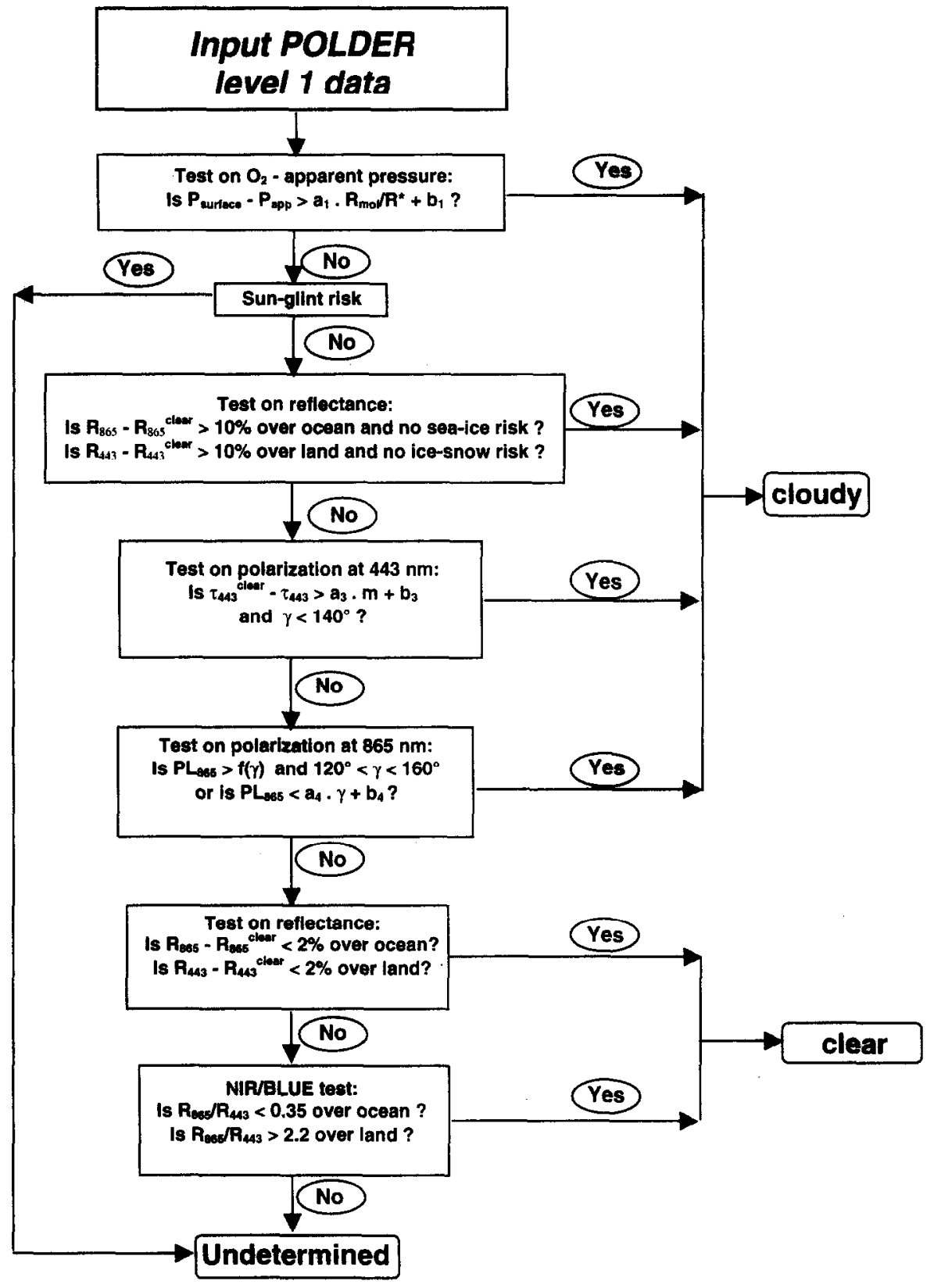

Fig.2. Outline of the part of the cloud detection algorithm applied to each pixel and for every viewing direction. 

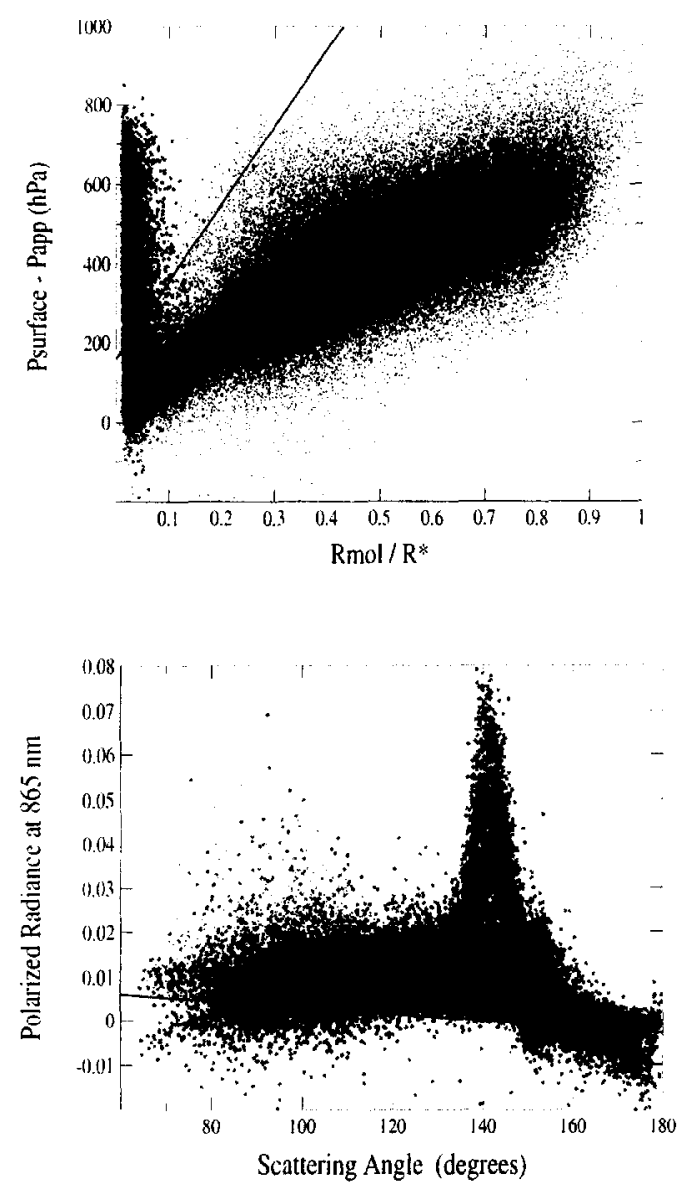

Fig. 3. (a) Difference between the sea-surface pressure and the "apparent" pressure as a function of the ratio between the molecular and the total reflectance. (b) Polarised radiance at $865 \mathrm{~nm}$ as a function of the scattering angle. The regular curves are the threshold lines. The black (grey) dors correspond to pixels for which $R_{865}-R_{865}^{\text {cleur }}<2 \%(>10 \%)$ in all the directions of view.

four lirst tests, the reflectance threshold test, $\mathrm{R}_{\lambda}-\mathrm{R}_{\lambda}^{\text {clear }}<$ $2 \%$ is considered as a reference test, i.e. all the pixels that satisfy this test for all the viewing directions are expected to be clear. This reflectance threshold test is used as an indicator of the relevance of the different "cloud" thresholds. At this stage, the philosophy of the cloud detection algorithm is to adjust the "cloud" thresholds in order to make sure that all the four tests prove negative when the pixel is clear. When detecting the cloud-free pixels, a similar approach is adopted. Pixels are expected to he "cloudy" if the reflectance threshold test, $\mathrm{R}_{\lambda}-\mathrm{R}_{\lambda}^{\text {clear }}>$ $10 \%$, is satisfied whatever the direction of view. The spectral variability thresholds are thus adjusted in such a way that practically no cloudy pixel is declared as clear. An illustration of that is shown in Fig. 3 for ocean pixels. Are reported the pixel values for which the two reference conditions on $R_{865}-R_{865}^{\text {clear }}$ are satisfied in all the viewing geometry.

If a POLDER pixel fails all of the six tests described above, it remains unclassified for a given viewing direction. However, if this pixel is labelled as clear (or cloudy) in some viewing directions and undetermined in all the other ones, then it is labelled as clear (or cloudy) for all the directions. If the pixel remains undetermined, it is then relabelled as clear or cloudy depending on the classification of the neighbouring pixels and the spatial variability of R865. Afterwards, when all of the elementary pixels are identified as cloud-free or cloudy the cloud cover is computed at the super-pixel scale $(\sim 9 \times 9$ pixels $)$, direction by direction.

\section{The METEOSAT cloud classification method}

A first validation of the POLDER pixel identification algorithm goes through a comparison with the results of the Dynamical Clustering Method (Sèze and Desbois, 1987) applied to METEOSAT data acquired every half hour between 7 and 14 UTC from 30 October to 10 November 1996. The spatial resolution of the METEOSAT data at nadir is $5 \mathrm{~km}$. The Dynamical Clustering Method makes use of two spectral parameters, the infrared and visible radiances and two structural parameters, the local spatial standard deviation of the visible and infrared radiances (computed for $3 * 3$ neighbouring pixels). These data are processed following Raffaelli and Sèze (1995) for five latitudinal regions over ocean and six regions over land. The result is a set of cloud type classifications valid between 7 and 14 UTC for the 30 October-10 November 1996 period. From this set, any ADEOS-POLDER path in the METEOSAT field of view can be simulated with a time lag of \pm 15 minutes.

\section{Comparison}

The POLDER and METEOS $\Lambda \mathrm{T}$ pixel identification methods are compared for the 3 ADEOS paths (orbit numbers 3107 to 3109 ) on 10 November. Figure 4 presents the respective pixel identification maps. The proportion of clear (overcast) pixels is $31 \%(44 \%)$ in the METEOSAT classification and $39 \%(52 \%)$ in the POLDER one. The smaller percentages in the METEOSAT classification are compensated by a larger percentage of partly cloudy pixels (small cumulus, cloud edges, very thin cirrus) than in the POLDER cloud classification. Note that the "partly cloudy" term has not the same meaning for METEOSAT and POLDER pixels. In the former, it is used for METEOSAT pixels that are expected to be partially covered by clouds. In the latter, it is used for POLDER pixels that are declared as completely cloudy in some viewing directions and clear in the others. The cooccurrence matrix obtained from the pixel-to-pixel comparison of the two classifications (Table 1) shows that 


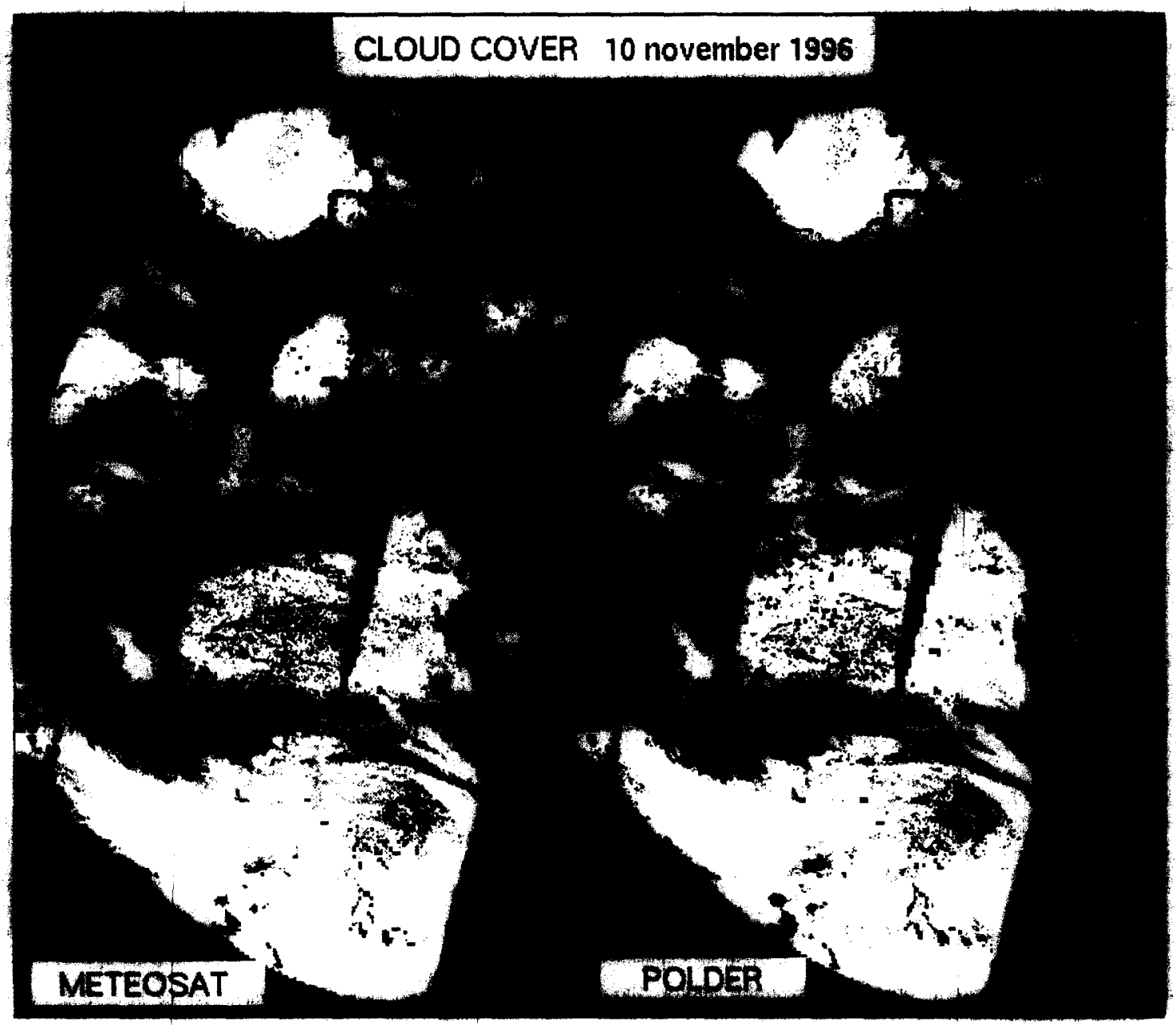

Fig. 4. Pixel identification maps constructed from METEOSAT and POLDER cloud identification schemes. Overcast pixels are in white, cloud-free pixels are in dark grey and partly cloudy pixels are in light grey. Black is used for background, coasts and lack of data.

$72 \%$ of the pixels belong to the same class and only $1.6 \%$ belong to opposite classes (clear/overcast or overcast/clear) over ocean. Over land $81 \%$ of the pixels belong to the same class and $4.5 \%$ belong to opposite classes, that highlights the greater difficulty of classifying pixels over land surfaces. The percentage of pixels declared clear by POLDER but declared cloud-contaminated by METEOSAT (11\% over ocean, $8 \%$ over land) is larger than the opposite case ( $2 \%$ over ocean, $4 \%$ over land). Once more it is associated to the larger number of partly cloudy pixels in the METEOSAT classification.

Tables 2 give the distributions of the METEOSAT cloud types for each of the 3 POLDER classes. The overcast cloud types (low, middle, multi-layer, cirrus, high thick clouds) have at least $81 \%$ of their pixels belonging to the overcast class in the POLDER classification and less than $8 \%$ of them are classitied as clear. An exception is the thin cirrus class for which the pixel identification is much more uncertain in particular over land. Generally speaking, for the ambiguous classes (in grey in Table 2) the percentage of clear POLDER pixels decreases as the sub-pixel cloud cover is expected to increase. Study of the spatial neighbouring of these partially covered METEOSAT pixels shows that when they are declared clear by POLDER, the percentage of clear METEOSAT pixels in the neighbouring is larger than in the other cases.

Table 1. Co-occurrence matrix obtained over ocean (over land) from the pixel-to-pixel comparison of METEOSAT and POLDER identification for the 3 POLDER-ADEOS paths of Fig. 1 .

\begin{tabular}{lccc}
\hline & \multicolumn{3}{c}{ POLDER } \\
METEOSAT & Clear & Partly & Overcast \\
\hline Clear & $19.1 \%(56.3 \%)$ & $1.2 \%(2.8 \%)$ & $0.8 \%(1.7 \%)$ \\
Partly & $10.5 \%(4.7 \%)$ & $5.8 \%(1.7 \%)$ & $13.2 \%(3.7 \%)$ \\
Overcast & $0.8 \%(2.8 \%)$ & $2.0 \%(3.5 \%)$ & $46.7 \%(22.9 \%)$ \\
\hline
\end{tabular}


Table 2. Distribution of the METEOSAT cloud types in each of the 3 POLDER classes for the ocean pixels (land pixels) of the 3 POLDERADEOS paths of Fig.l.

\begin{tabular}{|c|c|c|c|}
\hline \multirow[t]{2}{*}{ METEOSAT Cloud types } & \multicolumn{3}{|c|}{ POLDER classes } \\
\hline & Clear & Partly & Over \\
\hline $1.1 \%(60.8 \%)$ clear & $91 \%(93 \%)$ & & \\
\hline $122 \%(16 \%)$ hearlyclear & $619(22 \%)$ & $18 \%(13 \%)$ & $319(65 \%)$ \\
\hline $30968 \% 19$ & $38 \%(6 \%)$ & $29 \%(19 \%)$ & $32 \%(20 \%)$ \\
\hline $.37(1.6 \%)$ party cloudy & $13 \%$ & $14 \%(11 \%)$ & $73 \% 0$ \\
\hline $12.6 \%(1.0 \%)$ low clouds & $1 \%(0 \%)$ & $1 \%(0 \%)$ & $98 \%(99 \%)$ \\
\hline $7.2 \%(2.7 \%)$ middlc clouds & $3 \%(0 \%)$ & $6 \%(1 \%)$ & $91 \%(99 \%)$ \\
\hline $5.5 \%(6.5 \%)$ multi-layers & $0 \%(8 \%)$ & $1 \%(10 \%)$ & $99 \%(82 \%)$ \\
\hline $4.4 \%(5.5 \%)$ thin cirrus clouds & $7 \%(29 \%)$ & $20 \%(26 \%)$ & $73 \%(45 \%)$ \\
\hline $1.0 \%(10.0 \%)$ & $1 \%(6 \%)$ & $4 \%(13 \%)$ & $9.5 \%(81 \%)$ \\
\hline $3.0 \%(2.9 \%)$ high thick cloud & $0 \%(0 \%)$ & $0 \%(0 \%)$ & $100 \%(100 \%)$ \\
\hline
\end{tabular}

\section{Discussion and conclusion}

The cloud detection derived from POLDER compares well with the METEOSAT cloud classification on an instantaneous basis and at the pixel scale. The percentage of full agreement between POLDER and METEOSAT (74\%) is close to the $81 \%$ which is found by comparing the METEOSAT classification with itself by introducing a shifi of I pixel. However, in the last case, only $0.2 \%$ of the pixels are classified in opposite categories against $2.3 \%$ in the POLDER-METEOSAT comparison. This discrepancy between POLDER and METEOSAT classifications comes from the differences both in the observations and the algorithms. The METEOSAT algorithm is very sensitive to a very small spatial variability of radiance values close to surface ones. In the POLDER scheme, thresholds have been set up to avoid the inclusion of false clouds such as Saharan dust. When the apparent pressure threshold and/or the reflectance threshold is decreased. the percentage of clear POLDER pixels declared clear by METEOSAT increases, but the percentage of clear METEOSAT pixels declared cloudy by POLDER increases too. This comparison appears encouraging though there are some discrepancies over land especially for the partly cloudy and the thin cloud cases.

One has to kccp in mind that the aim of the "ERB \& clouds" processing line is to derive cloud properties and not to detect surface parameters. Consequently the cloud detection algorithm is very different from a cloud-clearing algorithm. The previous discussion highlights that the broken cloudiness or the thin cloud cover are sometimes classified as clear from the POLDER pixel identification scheme. In fact, one verifies that the different thresholds of the POLDER algorithm have been adjusted in such a manner that questionable cloud cases as well as thick aerosol layers are rejected as clear. Generally speaking, it seemed to the authors that it was preferable to not allocate to an entire POLDER pixel some mean cloud properties that correspond only to a small fraction of the pixel.

\section{Acknowledgements}

This work was supported by CNES, Région Nord-Pas de Calais. EEC and Préfecture du Nord through EFRO. Meteorological and METEOSAT data were courtesy provided by Météo-France.

\section{References}

Barkstrom, B.R. and Smith. G.L., 1986: The Earth Radiation Budget Experiment: science and implementation. Rer: Geophys.. 24. 379-390.

Buriez. J.C., Vanbauce, C., Parol, F., Goloub, P., Herman, M.. Bonnel, B. Fouquart. Y., Couvert. P., and Seze. G.. 1997: Cloud detection and derivation of cloud properties fiom POLDER. Int. J. Remote Sensing. 18, 278.5-2813.

Deschamps, P.Y., Breon, F. M., Leroy, M., Podaire, A., Bricaud, A., Buriez, J. C., and Seze, G., 1994: The POLDER mission: Instrument characteristics and scientific objectives. IEEE Truns. Geosci. Rem. Sens, 32, 598-615.

Goloub. P., Deuzé. J.-L., Herman, M., and Fouquart. Y.. 1994: Analysis of the POLDER polarization measurements performed over cloud covers IEEE Trans. Geosci. Rem. Sens. 32. 78-88.

Parol, F., Buriez, J.C., Vanbauce, C., Couvert, P., Sèze. G., Goloub, P., and Cheinet, S., 1999: First results of the POLDER "Earth Radiation Budget and Clouds" operational algorithm. IEEE Truns. Geosci. Rem. Sens. In press.

Raffaelli, J. L. and Sèze. G., 1995: Cloud type separation using local correlation between visible and infrared satellite images, in Passive Infrared Remote sensing of clouds and the atmosphere III. Proc. SPIE 2578, 61- 67 .

Schiffer, R. A. and Rossow, W. B., 1983: The International Satellite Cloud Climatology Project (ISCCP): The first project of the World Climate Research Plogram. Bull Amer. Metern. Soc., 64, 779-784.

Sèze, G. and Desbois, M., 1987: Cloud cover analysis in satellite imagery using spatial and temporal characteristics of the data. J. Climate Appl. Meteor., 26, 287-303.

Vanbauce. C., Buriez, J.C., Parol, F.. Bonnel, B., Sèze, G., and Couvert, P.. 1998 : Apparent pressure derived from ADEOS-POLDER observations in the oxygen A-band over ocean. Geophys. Res. Letters,. 25, 3159-3162. 